\title{
LA ESPAÑA POSIBLE DE JULIÁN MARÍAS
}

\section{THE POSSIBLE SPAIN OF JULIAN MARIAS}

\author{
Rafael HerRera GuilLÉN* \\ UNED
}

A María Teresa Román, alegre y cálida siempre.

In Memoriam.

Resumen: Este trabajo analiza la actualidad del libro de Julián Marías La España posible en tiempo de Carlos III. Consideramos que la perspectiva de Marías acerca del siglo XVIII español constituye un relato indirecto sobre su propio tiempo histórico. La tarea real para Marías era encontrar una España posible para el futuro. Pues bien, ese futuro es nuestro presente; y la tarea es la misma: hallar una Espańa posible. Al igual que Marías, este trabajo afirma que el siglo XVIII espańol puede orientarnos en la tarea de construir nuestro presente político.

Palabras clave: Julián Marías, Ilustración, Jovellanos, Sempere y Guarinos, reformismo, liberalismo, España.

\footnotetext{
* Profesor en el Departamento de Filosofía. E-mail: rherrera@uned.es
} 
Aвstract: This article analyzes the current pertinence of La España posible en tiempo de Carlos III. I consider Julian Marias' view of the Spanish eighteenth century to be an indirect narrative about his own historic time. To find out a possible Spain for the future was his real target. Having said that, we are now clearly aware that this future is our present; our target is the same: finding a possible Spain. Just like Marias' work, this paper suggests that the eighteenth century in Spain can guide us in the hope of building our political present.

KeY wORDs: Julian Marias, Enlightenment, Jovellanos, Sempere y Guarinos, Reformism, Liberalism, Spain.

\section{Historiografía de la normalidad e historiografía de la excepción}

Las tesis del prólogo de La España posible del tiempo de Carlos III jalonan todo el libro e inspiraron las mías a la hora de trabajar aquel siglo hace ya algunos años. Fue la española, a su juicio, una Ilustración más responsable, bien que, con sus contradicciones, y es verdad que aquella España posible se desvaneció por causas externas mal digeridas por un caldo de cultivo interno.

La ilustración española, menos brillante que la francesa, menos apoyada por la sociedad, incomparablemente menos aireada y promovida por la propaganda, era mucho más responsable. La irresponsabilidad intelectual que domina casi toda Europa desde el siglo XVIII -véase mi libro España inteligible si se quiere comprobarlo- fue casi enteramente ajena a los modestos, veraces, esforzados intelectuales españoles de aquel tiempo ${ }^{1}$.

\footnotetext{
1 Marías (1988: 6).
} 
Esta peculiaridad responsable y moderada de la Ilustración española procede de su menor confianza en la consideración de la razón como poder absoluto. El hecho de que no se perdiera la noción de que hay otras fuentes de autoridad, si bien compatibles con la razón, como la costumbre e instituciones como la Iglesia, hizo que la Ilustración española ejerciera un racionalismo crítico moderado, vinculado a la reforma, y siempre alejado de la transformación radical revolucionaria. Se puede decir que, mientras la Ilustración francesa, en buena tradición cartesiana, tuvo como axioma "que la realidad se debe ajustar a los dictámenes de la razón» ${ }^{2}$, la Ilustración española siguió el camino de insertar los dictámenes de la razón en los espacios de la realidad reductibles y permeables a las reformas. La cualidad propia de la Ilustración española es su responsable centrismo crítico. Desde luego que esta actitud estuvo condicionada tanto por convicciones intelectuales como por las cautelas respecto de los peligros que podía implicar para ellos romper con la tradición ${ }^{3}$.

Algunos críticos, sin embargo, han esgrimido precisamente esta falta de radicalidad del racionalismo ilustrado español como la prueba fáctica de su parcialidad, de su insuficiencia e incluso de su inexistencia ${ }^{4}$. No obstante, quienes hablan así, caen en la circularidad de analizar el problema sobre las mismas bases originarias del absolutismo de la razón ilustrada. Marías ha escrito que «lo que

\footnotetext{
2 «Lo característico de esta actitud, lo específicamente racionalista, es la creencia en que la realidad se debe ajustar a los dictámenes de la razón, que ésta puede imponerle sus normas, que no hay una estructura de lo real capaz de rechazarla o exigir que el pensamiento se adapte a ella. La consecuencia es triple: universalidad, utopismo y predominio del wishfull thinking o pensamiento desiderativo.» Marías (1998: 20).

3 «Y hay que agregar que, sin duda por el peso de la tradición y por las cautelas con que tenían que moverse los ilustrados españoles, éstos no pudieron nunca olvidar la realidad con que se enfrentaban y principalmente las fuerzas que se oponían a sus proyectos. En este sentido, la Ilustración española apenas fue utópica y ciertamente no fue extremista. Las figuras de los grandes ilustrados -Feijoo, Macanaz, Jovellanos, Cadalso, el P. Andrés, Moratín- parecen extrañamente responsables. Quizá sus virtudes fueron menos brillantes que las de los "ilustrados" de otros paises, pero sus defectos fueron también menores. Inventaron menos -pero todos vivian de la herencia del gran siglo anterior-pero erraron muy poco y salvaron una enorme porción del pasado que seguía siendo válido.» Marías (1998: 25).

4 En relación a este problema historiográfico y de fondo filosófico, Amable Fernández Sanz, aunque no cita a Marías, sigue las tesis y la nomenclatura de éste, cuando escribe que, frente a quienes niegan valor a las luces españolas: «Nos inclinamos, pues, por hablar de Ilustración posible ya que, con ellos, por un lado, se alude a las dificultades y condicionantes que tuvieron que afrontar nuestros ilustrados $y$, por otro, no resta valor a su contribución, positiva y evidente, para la modernización de España» Fernández Sanz (2002: 130).
} 
caracteriza al pensamiento ilustrado es su voluntad de innovación, frente a las actitudes tradicionales y que conservan el respeto a los "modelos", a los "clásicos" "5.

No obstante, esto tuvo sus distorsionadores reflejos en la ciencia histórica. Se impuso el prejuicio de la jerarquización según el cual, sólo los hombres y las culturas «innovadoras» podían ocupar el lugar más eminente en la narración del historiador. Este error de la historiografía y, en general, de los métodos usuales de comprender el pasado, relaciona originalidad con genialidad en lo personal y con revolución en lo político. Frente al prejuicio de la excepcionalidad historiográfica, nos gustaría proponer aquí, apoyados en trabajos como el de Marías, el paradigma de la normalidad historiográfica, que relaciona normalidad con magisterio en lo personal y reforma en lo político. Desde luego, un trabajo historiográfico serio debe tener en cuenta ambas situaciones objetivas como sucesos históricos posibles, evitando críticamente toda jerarquización. De este modo, un historiador competente es aquel que sabe valorar en su legítima trascendencia a Rousseau sin menospreciar la influencia de Jovellanos.

Se suele decidir la importancia de los autores por su originalidad, por ser aquéllos que abren caminos y tienen una influencia decisiva. Esto es justo, y ha de hacerse, pero no a condición de olvidar la normalidad, por así decir, de olvidar que la historia se construye, no a base de excepciones y originalidades, sino en un proceso de normalidades. Tener conciencia de esto justificaría que se estudiara la importancia de Rousseau, e impediría que se olvidara que hombres como Jovellanos, que no fueron originales en sus aportaciones, tuvieron una autoridad de magisterio epocal fundamental.

El magisterio moral es tan importante como el magisterio intelectual. No sólo las obras de los hombres son patrimonio de la historia, también sus existencias, sus biografías, constituyen valiosos tesoros históricos, que dotan a sus obras de una luz propia, que si bien no se sostienen por la excepcional genialidad, se fundamentan en la sobriedad del maestro, cuya actitud es la lección de un tiempo. Occidente, Grecia, nunca desgajó su sentido del tiempo entre obra escrita y existencia magistral. Sócrates es la prueba testimonial más arquetípica de esta cuestión. Platón de hecho escribió contra la escritura, es decir, contra la preeminencia de la obra sobre la vida.

5 Marías (1998: 22). 
El magisterio es una dimensión existencial, dialógica -y sólo secundariamente es un objeto textual. La vida puede constituir la mayor obra intelectual del sujeto moral. La revolución francesa, la sed de novedad, el prestigio de la excepción, dotaron al texto y al sujeto genial de un aura que rompió una cadena de prestigio que Europa debiera recomponer, para así recuperar el hontanar de la vida ejemplar, de la existencia magistral como categoría histórica fundamental.

Desde esta perspectiva, la España de Carlos III y la ilustración española tienen el derecho a ser reconocidas como períodos fundamentales de las luces. Hombres como Jovellanos son tesoros inmarcesibles, obras maestras escritas en la vida misma.

En La España posible Marías afirma de pasada acerca de Feijoo que su importancia no radica en su altura intelectual, sino en lo que denomina como su «actitud moral -se entiende, de moral intelectual, muy superior a sus "dotes" ${ }^{6}$. Pues bien, esta «actitud moral e intelectual» es la clave para entender la lectura de Marías respecto de nuestro siglo XVIII, pues es el suyo un acercamiento intelectualmente riguroso a la vez que moral y socialmente responsable.

\section{La España posible de Carlos III}

Cada época de una vida personal o de la historia de un país, constituye una cristalización de múltiples posibilidades que, abiertas en el pasado, movilizaron las energías proyectivas de un hombre o de una nación. Las ideas orteguianas de la circunstancia y de la esencia proyectiva de la vida son aplicadas por Marías para examinar la Espańa «posible» de Carlos III.

Sobre esta base filosófico-metodológica, «España posible» significa la indagación, no de un futurible fantasioso, sino de una posibilidad histórica real que pudo ser objetivamente, pero que, la circunstancia, en su multiplicidad de azares y libertad, impidió llegar a ser. Una posibilidad histórica de un ente político, así pues, implica una energía detenida, que espera su efectividad histórica, si las

6 Marías (1988: 94). 
condiciones favorables se producen. Es como un camino que, durante un tiempo, ha quedado sellado como un callejón por los muros de un discurrir temporal, pero que, en un presente determinado, puede ser abierto al tiempo, derruyendo los obstáculos?.

Pues bien, el espíritu del XVIII español es el del «espíritu crítico». Los ilustrados españoles son críticos tanto para conservar como para progresar. De hecho, en ellos ambas posiciones se unen de un modo evidente. La escisión entre ideas progresistas y conservadoras es fruto posterior. En las obras y actitudes sociales y morales de los hombres ilustrados, los hombres del centrismo critico, el camino hacia el futuro debía marcarse en base a la introducción de todos los usos y saberes nuevos del progreso en el seno de una sociedad que, transformándose, conservara no obstante el núcleo sustancial de su sentido histórico. Esta, a mi juicio, es la España posible, la España centrada, progresista y responsable, inteligentemente liberal, que perdió la batalla en los enfrentamientos posteriores a 1808. Marías cita un fragmento clave del famoso Apéndice a la educación popular de Campomanes, de 1776.

De cada nación debemos imitar lo mejor que hace: de esa suerte con ser meros copiantes de sus adelantamientos por ahora, reteniendo lo bueno que tengamos, acomodándoles a nuestros usos, llegaremos a estar al nivel de las demás naciones en breve tiempo, haciéndonos dóciles para adoptar lo que ignoremos, o no sepamos hacer tan bien, como el extranjero ${ }^{8}$.

Invoca la figura de Campomanes para incidir en la diferencia de la templada actitud del asturiano, con respecto a posiciones pre-reaccionarias como la de la Oración apologética de Forner, de $1786^{\circ}$, que una década después de obras como la de Campomanes, comenzaron a poner en funcionamiento una especie de irresponsable narcisismo cultural, una especie de cerril autocomplacencia

\footnotetext{
7 «De un modo análogo, solamente preguntándose por la España que pudo ser resulta posible entender la España que ha sido.» Atencia (2007: 272).

8 Campomanes, Apéndice a la educación popular, parte tercera, Madrid, 1776, pp. 12-14, cit. por Marías (1988: 68-69).

9 Recuérdese que en 1936 ediciones Fe publicó una selección de textos de Forner.
} 
alérgica al aperturismo, que venía a compensar desabridamente el desprestigio internacional de España ${ }^{10}$.

El texto central de Campomanes señala la actitud fundamental del espíritu crítico de nuestra Ilustración. Su objetivo era incorporar los adelantos prácticos extranjeros, «hacer» como ellos, pero no «ser» ellos. Sin embargo, con el estallido de la revolución francesa, este "hacer como» se interpretó como un peligroso camino hacia el «ser como».

El adelanto en las ciencias y en la economía de Europa se consideraron instrumentos ponzoñosos que podían afectar a la sustancia del orden social e idiosincrático español. El antecedente sintomático inmediato de este cierre social y político lo constituyeron, a juicio de Marías, las apologías acríticas, sobre todo la de Forner, escritas por encargo de Floridablanca, cuya política exterior de cierre respecto a Francia para establecer el cordón sanitario anti-revolucionario fue definitivo para suspender el proceso moderado de ilustración -que antes había apoyado ${ }^{11}$.

Frente a apologistas y críticos exacerbados, Marías invoca la figura de un autor fundamental: Juan Sempere y Guarinos. Marías le caracteriza como un ilustrado centrado y sobrio, de quien elogia su Ensayo de una biblioteca de los mejores escritores del reinado de Carlos III, como obra de carácter crítico y morigerado ${ }^{12}$. De hecho, la actitud sosegada de Sempere fue muy acremente vilipendiada por Forner, quien como era su costumbre, rebajó su mérito (en realidad intelectualmente muy superior al suyo) afirmando que la obra de Sempere sólo servía para que los pescaderos envolvieran su mercancía con sus páginas. Marías no aborda esta relación Forner-Sempere, pero tiene la poderosa intuición de contrastar ambas actitudes sobre el problema de España, para ponerse con toda evidencia del lado de la crítica inteligente, ajustada y abierta, pero a la vez patriótica, de Sempere. De éste cita el siguiente pasaje, en donde el autor expresa el sentido de

10 Fundamentalmente los ataques de Morvilliers. Vid. Víctor Cases. La España de la Encyclopédie méthodique de 1782. http://www.saavedrafajardo.org/archivos/libros/libro0665.pdf.La versión española de 1792 del polémico artículo de Masson de Morvilliers

11 Marías (1988: 74). Esta idea del cierre de Espańa por Floridablanca la defendió sobre todo Richard Herr (1988). En la actualidad ha sido puesta en cuestión por autores como Enrique Álvarez Cora (2009).

12 Sobre la figura y el pensamiento de Juan Sempere y Guarinos, vid. el estudio de Herrera (2007). 
su actitud: "Yo estoy muy lejos de querer entrar en el número de aquellos que tienen por un rasgo de ingenio criticar a su nación, y a sus paisanos. Mas para dar alguna idea de nuestra literatura actual, se hace preciso el saber el estado en que estaba a principios de este siglo». ${ }^{13}$

Y este estado, a su juicio, fue lamentable porque la herencia del siglo XVII había dejado a España en un nivel cultural que no merecía apología alguna y que, en todo caso, comenzó a superarse por el esfuerzo que las mentes ilustradas empezaron a llevar a cabo con la ascensión al trono de Felipe V. Por tanto, de modo indirecto, Sempere también se posicionó muy lejos de cuantos hicieron la apología española de un modo retórico, ajeno al espíritu de seriedad autocrítica que el polígrafo alicantino encarnaba. De hecho, Marías describe así la actitud de Sempere que, en el fondo, también era la del propio Marías, en su circunstancia, obviamente: "Lo que Sempere pretende es demostrar que "nuestra Nación piensa ahora bien por lo general." Me parece admirable la moderación y el acierto de esa expresión sencilla, tan lejos de la hipérbole como de la falsedad $»^{14}$.

Y para que se calibre el justo medio responsable que Marías atribuye a Sempere como cualidad más esencial de nuestra Ilustración, el maestro vallisoletano invoca un texto fundamental del ilustrado, con el fin de evidenciar que, para nuestra Ilustración, la crítica abierta de los males de Espańa no sólo no estaba en contradicción con un fuerte sentido patriótico, sino que, incluso, esta labor crítica del estado de las letras del país era prueba ella misma de amor por la patria. De hecho, el Ensayo de una biblioteca de los mejores escritores de Carlos III es un libro de crítica cultural pensado como herramienta de unidad política. Así, Sempere explica por qué en su libro ignora el origen provincial de los autores de este modo: «Mientras una nación no llegue a consolidar en su seno el espíritu de unidad y de patriotismo, le faltan todavía muchos pasos que dar en la civilización. No es el mejor medio para extinguir la rivalidad de las provincias, el referir por menor las patrias de sus Escritores. Antes, acaso, convendría sepultarlas en el olvido, a lo menos por cierto tiempo, y que de ningún hombre de mérito de nuestra nación no se pudiera decir más que es Español» ${ }^{15}$.

13 Cit. por Marías (1988: 76).

4 Marías (1988: 79).

5 Marías (1988: 79) Sobre el patriotismo semperiano y sobre este fragmento en particular, vid. el examen de Herrera (2007a) IV, especialmente pp. 161-169. 
Por tanto, la idea que Marías tiene de la Ilustración española constituye el antecedente respecto de su situación propia ante sus contemporáneos. Se trataba de insistir en que el pasado y el patriotismo no son patrimonio de la reacción, sino antes al contrario, el progresismo reformista, que mira tanto al presente y al futuro como a la memoria de los ancestros, constituyó a su juicio la mejor herencia de nuestra Ilustración.

Y esta herencia, al cabo, era la que podía sacar a España del marasmo de posguerra, incidiendo en la idea de que el aperturismo a las corrientes de la época no sólo era un modo de fidelidad patriótica, sino que era el verdadero modo de cumplir con el servicio al país. Esta indirecta apelación permanente a su propia circunstancia se observa en todos los fragmentos que Marías cita de nuestro siglo XVIII. Y respecto de la idea que acabamos de señalar según la cual el progresismo reformista y crítico es el modo superior de patriotismo, queda de manifiesto en este párrafo que cita del duque de Almodóvar, Pedro de Luxán: «Acordémonos de nuestros abuelos, y compendiando los progresos del siglo presente, armemos otra vez la máquina con que vuelva a alzarse el honor de la nación al grado que merece, y se ponga en el debido movimiento la reputación que debe recobrar, y a que es acreedora» ${ }^{16}$.

Pero el centrismo crítico de la Ilustración española comenzará a abandonarse, a arrinconarse y finalmente a ser perseguido por lo que Marías sintetiza en la idea de "radicalización inducida» ${ }^{17}$. Fecha este cambio en el espíritu del tiempo que comienza a aflorar en el final del reinado de Carlos III y la reacción antifrancesa producida ante el temor revolucionario de 1789. Es entonces cuando se produce un enquistamiento de las posiciones reaccionarias más ultramontanas, que señalan cualquier atisbo de apertura como peligroso poso revolucionario. Con fina persuasión, Marías afirma que, desde entonces, se produjo una «desfiguración que inventa la calumnia de "una ilustración extremista, revolucionaria e impía que nunca existió" en España, y asegura que esta deformación de la realidad histórica aún no ha terminado» ${ }^{18}$.

16 Sección "Al lector» de Década epistolar sobre el estado de las letras en Francia, en Marías (1988: 98).

17 Marías (1988: 109).

18 Marías (1988: 112).

ÉNDOXA: Series Filosóficas, n. 42, 2018, pp. 343 -354. UNED, Madrid 
Entonces Marías recuerda que este despeñamiento por la reacción llegó al límite de incoar procesos contra leales patriotas probados como Jovellanos ${ }^{19}$. Este olvido del patriotismo de los mejores, de la lealtad bien entendida como liberal templanza, era también la realidad contemporánea de Marías. Desde esta interpelación permanente a su presente hay que leer sus libros sobre el XVIII y, en este sentido, se comprende su análisis de Jovellanos, que es tanto como un análisis de las persecuciones de la posguerra. Historia y biografía, idea y existencia, se correlacionan en el espacio íntimo del análisis riguroso del pasado.

Desde esta perspectiva, debe leerse este espléndido pasaje de Los españoles: "Cayó el negro telón sobre la escena que acababa de llenar Jovellanos, y quedó este fuera de ella. Durante siete años, siete ańos decisivos, Jovellanos estuvo preso. ¿Hay algo más injusto y lamentable? Sí: durante esos mismos siete años, España se quedó sin Jovellanos» ${ }^{20}$. Podría sugerirse que, el fondo que fertiliza existencialmente este fragmento es el emocionado homenaje del discípulo a su maestro, Ortega, recluido en el silencio, en su pequeño Bellver madrileño, desde donde intentaba fomentar las luces y la libertad con su discípulo a través del Instituto de Humanidades, del mismo modo que Jovellanos trabajó por su patria desde el Instituto de Gijón.

\section{Exilio estatal y arraigo social}

Todo este estudio de la historia española del siglo XVIII fue una derivación necesaria de la actitud personal e intelectual de Marías respecto de su presente ${ }^{21}$.

19 De hecho, Marías señala como pauta común en la evolución de los ilustrados españoles, el paso desde las esperanzas en tiempo de Carlos III a la desesperanza a partir de Carlos IV y Fernando VII, que explica también una suerte de involución en alguno de ellos, respecto de sus posiciones ilustradas y aperturistas de su juventud. «Creo percibir en la obra de Capmany ese desaliento que sobrecoge a la mayoría de los ilustrados espańoles cuando pasan de Carlos III a Carlos IV o la Guerra de la Independencia - no digamos a Fernando VII-. De la época llena de esperanza en que el futuro parecía suyo, a aquella otra en que la Revolución francesa y su aprovechamiento por las fuerzas reaccionarias espańolas han hecho que la Ilustración, sin haber acabado de llegar, sea ya cosa del pasado. La misma desesperanzada actitud que encontramos al final de las vidas de Jovellanos, Meléndez Valdés, Moratín. Desengaño de Europa, desilusión de España se mezclan amargamente en esas vidas que eran alegres llamas hacia lo alto...». Marías (1988: 170-171).

20 Marías (1966: 57).

21 José Ma Atencia Páez, recuerda que en «Hacia la historia de España», aparecido en $A B C$, 6 VII, 2000, Julián Marias afirmaba que "empezó a indagar en el ser histórico de España desde 
Su actitud frente a la España franquista permea su estudio histórico, pero sólo puede comprenderse bien, si entendemos la dimensión moral de responsabilidad que Marías atribuyó a su tarea. Sobre todo, debemos de tener en cuenta que Marías, aun residiendo en España, vivió una forma de exilio asumido. Marías se exilió del Estado español, no de la sociedad española. En esta actitud hay una interpretación existencial de las palabras del maestro, Ortega, cuando en Vieja y nueva política distinguía la «Espańa oficial» de la «España vital». Aquello posible, y que fue abortado, fue la España liberal, en el sentido profundo del término. Los ilustrados de Carlos III fueron los preliberales que no tuvieron continuidad posible a causa de las radicalizaciones reaccionaria y revolucionaria. Esto sucedió en el XIX español, pero también fue la causa, en último término, de la Guerra Civil. Ambos bandos compartían un profundo odio al liberalismo. En 1964, Julián Marías escribió: "Yo creo que la democracia es admirable si es democracia liberal, pero no si no lo es» ${ }^{22}$. Hoy se pone en tela de juicio si esa España posible renació en 1978. Desde luego, las pulsiones sectarias que desangraron al país durante la contienda civil fueron neutralizadas en una normalidad que, no obstante, a veces deja asomar los dientes de una inercia histórica peligrosa ${ }^{23}$. Pero que esta España posible de la democracia y de la libertad arraigue en las profundidades de las futuras generaciones, requiere de medidas de responsabilidad intelectuales y políticas. Marías nunca ejerció en la academia española. No basta con que nuestras élites intelectuales conozcan la historia de España. Es fundamental conocer el pensamiento que nutrió el tiempo histórico hispánico. Es por ello, por lo que constituye un déficit fundamental el hecho de que materias como la historia o el pensamiento filosófico español no formen parte del currículo de muchas Facultades españolas. Desde luego, una formación filosófica española, si quiere ser europea, si quiere ser global, ha de arraigar en una tradición compleja y rica como el pensamiento español. Es la sobria exigencia de que pensar en espańol constituye el camino para construir un futuro de libertad y progreso.

\footnotetext{
lo particular y concreto, y que la historia española como tal tardo en convertirse en centro de su atención». José Ma Atencia Páez (2007: 237).

22 Zamora Bonilla (2007: 218).

23 Esta cuestión se la plantea igualmente Javier Zamora, cuando sugiere que «sería interesante ver en qué medida lo que Marías entendía que hubiera sido La España posible en tiempo de Carlos III, se ha realizado... hoy en dia». En Zamora (2007: 219).
} 


\section{Bibliografía}

Álvarez cora, Enrique (2009). "Papeles inquisitoriales de la Revolución francesa" Res publica 22, pp. 301-324.

Atencia páez, José Ma (2007). «La identidad de España y los españoles en la obra de Julián Marias», en José Ma ATENCIA PÁEZ (ed.), Julián Marias. Una filosofía en libertad. Málaga: Servicio de Publicaciones e Intercambio Científico de la Universidad de Málaga, pp. 237-282.

Cases, Víctor (17892). La España de la Encyclopédie méthodique de 1782 [URL: http://www.saavedrafajardo.org/archivos/libros/libro0665.pdf.]

Fernández Sanz, Amable (2002). "Tradición y modernidad ilustrada”, en Manuel Maceiras Fafián (ed.). Pensamiento filosófico español. Vol. II. Del Barroco a nuestros dias. Madrid: Síntesis.

Herr, Richard (1988). España y la revolución del siglo XVIII. Madrid: Aguilar.

Herrera Guillén, Rafael (2007). Las indecisiones del primer liberalismo español. Juan Sempere y Guarinos. Madrid, Biblioteca Nueva.

Marías, Julián (1988). La España posible en tiempo de Carlos III. Barcelona: Planeta.

- (1966). Los españoles. En Obras. Madrid: Editorial Revista de Occidente.

Sempere y Guarinos, Juan (2007). Cádiz, 1812. Observaciones sobre las Cortes y sobre las leyes fundamentales de España. Memoria primera gótico-española. Madrid, Biblioteca Nueva. Edición y estudio preliminar de Rafael Herrera Guillén.

- (2011). Historia de las Cortes de España. Madrid. Centro de Estudios Políticos y Constitucionales. Edición y estudio preliminar de Rafael Herrera Guillén.

Zamora Bonilla, Javier (2007). «Julián Marías, en la senda liberal», en José Ma Atencia Páez (ed.), Julián Marías. Una filosofía en libertad. Málaga: Servicio de Publicaciones e Intercambio Científico de la Universidad de Málaga, pp. 205-219.

Recibido: 28/12/2017

Aceptado: 15/10/2018

Este trabajo se encuentra bajo una licencia de Creative Commons ReconocimientoNoComercial-SinObraDerivada 4.0

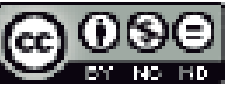

ÉNDOXA: Series Filosóficas, n. 42, 2018, pp. 343 -354. UNED, Madrid 